\title{
Diazotrophic Bacteria and Their Mechanisms to Interact and Benefit Cereals
}

\author{
Vânia Carla Silva Pankievicz, ${ }^{1}$ Fernanda Plucani do Amaral, ${ }^{2, \dagger}$ Jean-Michel Ané, ${ }^{1}$ and Gary Stacey ${ }^{2}$ \\ ${ }^{1}$ Department of Bacteriology, University of Wisconsin-Madison, Madison, WI, U.S.A. \\ ${ }^{2}$ Divisions of Plant Sciences and Biochemistry, C. S. Bond Life Science Center, University of Missouri, Columbia, MO, U.S.A.
}

Accepted 4 February 2021.

Plant-growth-promoting bacteria (PGPB) stimulate plant growth through diverse mechanisms. In addition to biological nitrogen fixation, diazotrophic PGPB can improve nutrient uptake efficiency from the soil, produce and release phytohormones to the host, and confer resistance against pathogens. The genetic determinants that drive the success of biological nitrogen fixation in nonlegume plants are understudied. These determinants include recognition and signaling pathways, bacterial colonization, and genotype specificity between host and bacteria. This review presents recent discoveries of how nitrogen-fixing PGPB interact with cereals and promote plant growth. We suggest adopting an experimental model system, such as the Setaria-diazotrophic bacteria association, as a reliable way to better understand the associated mechanisms and, ultimately, increase the use of PGPB inoculants for sustainable agriculture.

Keywords: bacteria-plant symbiosis, biological nitrogen fixation, cereals, genetics and gene regulation, non-rhizobium nitrogen fixation, PGPB, plant growth-promoting bacteria, Setaria viridis

Plant-associated microbes play an essential role in plant growth and development. In particular, cereals interact with diazotrophic bacteria that can fix atmospheric nitrogen, producing ammonia usable by the plant (Peoples et al. 1995). This mechanism is known as biological nitrogen fixation (BNF). To complete their life cycle, plants consume various nutrients such as nitrogen, phosphorus, potassium, and carbon. However, plants also release nutrients that can be used by microbes and, indeed, the rhizosphere, in general, has significantly higher microbial numbers than found in fallow soil (Peiffer et al. 2013). Microbes and plants in close association coordinate their metabolic activities by exchanging and recognizing diffusible signals. For example, this has been studied in great detail in the rhizobia-legume and legumearbuscular mycorrhiza symbioses, where the so-called common symbiosis pathway (CSP) allows the recognition of both symbionts as a consequence of the evolutionary link between these two symbioses (Gourion et al. 2015; Oldroyd 2013; Roy et al. 2020). The molecular components of the CSP are required for successful rhizobial colonization and nodule induction. In contrast, the

${ }^{\dagger}$ Corresponding author: F. P. do Amaral; doamaralf@missouri.edu

Funding: Department of Energy grant number DE-SC0014377 to J.-M. Ané and National Science Foundation grant award IOS-1734145 to G. Stacey.

The author(s) declare no conflict of interest. establishment of rhizobia as endophytes in rice does not require the CSP (Chen and Zhu 2013). Similarly, the CSP genes do not seem involved in the interaction of rice with associative bacteria such as the endophyte Azoarcus BH72 or the epiphyte Azospirillum brasilense (Chen et al. 2015, Thomas et al. 2019).

Compared with research in legumes, associations of monocotyledonous plants with beneficial microbes, especially epiphytic or endophytic diazotrophic bacteria, are far less studied (Chen et al. 2015; Eskin et al. 2014; Rosenblueth et al. 2018). The intense interest in rhizobia-legume interactions is due to the bacteria's ability to fix nitrogen inside the root nodule efficiently. The application of rhizobia in agricultural systems (e.g., soybean) helps decrease the amount of nitrogen fertilizer used on these crops, consequently reducing adverse environmental effects, improving sustainability, and reducing production costs. The fact that cereals do not nodulate has long been a frustration because it limits that ability to bring the advantages of BNF to the world's most important food crops (e.g., wheat, maize, rice, and so on) and bioenergy crops (e.g., sorghum, switchgrass, and so on). Genetics in model plant species (i.e., Lotus japonicus and Medicago truncatula) and their associated symbionts have significantly accelerated research on the legume-rhizobia and legume-mycorrhiza symbioses. Thus, it seems reasonable that the adoption of model species could similarly stimulate research on plant-growth-promoting bacteria (PGPB)-grass interactions. The adoption of Setaria viridis as a potential model to study BNF was demonstrated when association with A. brasilense and Herbaspirillum seropedicae provided up to $100 \%$ of the nitrogen needs of the plant (Pankievicz et al. 2015). Since then, S. viridis has been successfully used to describe the effects of beneficial nitrogen-fixing associative interactions in a more mechanistic and detailed manner than the numerous studies simply describing the phenomenology of nitrogen fixation in crops.

\section{HOW CEREALS RESPOND TO THE DIAZOTROPHIC BACTERIAL ASSOCIATION}

Soil bacteria associate in several ways with plant roots to promote plant growth. First, $\mathrm{N}_{2}$-fixing bacteria provide ammonia for plant growth and enhance root nutrient uptake, such as iron or phosphorus (Glick 2012). Second, plant hormones are essential for plant growth and development. Phytostimulation occurs when soil bacteria produce plant hormones like indole-3-acetic acid (IAA), gibberellic acids, cytokinin, and certain volatile organic compounds. Modulation of plant hormones by PGPB can enhance plant nutrient uptake and response to stress, which mediates plant growth (Glick 2012). Third, soil bacteria can enhance plant immunity; thus, beneficial and pathogenic microbes may be distinguished during the interaction (Glick 2012). 
Depending on the bacterial species or strains, specific stimulatory molecular pathways or metabolic adaptations are triggered in host plants, which directly or indirectly influence plant growth and development (Glick 2012). The review below focuses strictly on diazotroph-plant associations and, hence, excludes related topics (e.g., disease-suppressive soils), which are covered extensively in a variety of other reviews (Backer et al. 2018; Mendes et al. 2013; Trivedi et al. 2020).

\section{Role of biological nitrogen fixation.}

Plants associate intimately with diverse bacterial species benefitting both organisms through a nutrient exchange. PGPB have a considerable effect on the host's growth and development, increasing both plant health and yield. Cereals require a significant amount of nitrogen fertilizer for higher production. The application of diazotrophic bacteria that can contribute to nitrogen uptake by BNF has long been investigated under laboratory conditions. From the 1950s to the 1970s, primarily through the efforts of Dr. Johana Döbereiner and collaborators, numerous bacterial strains were isolated and shown to contribute to nitrogen fixation when associated with plants (Boddey et al. 1986; Cavalcante and Dobereiner 1988; Dobereiner 1961; Von Bülow and Döbereiner 1975). In the late 1980s, quantifying nitrogen abundance was used to determine the BNF contribution in planta. Based on these methods, it was demonstrated that sugarcane could acquire nitrogen from BNF, putting the Brazilian experience with sugarcane as a notable example of how diazotrophs can contribute to cereal culture (Baldani and Baldani 2005; Baldani et al. 1997; Boddey et al. 2001, 2003). Until today, BNF has continued to have a crucial effect on sugarcane; for example, a recent study reported that diazotrophic bacteria contribute up to $65 \%$ of the nitrogen content of two sugarcane cultivars grown under field conditions (Martins et al. 2020).

Although many publications have appeared describing the impact of diazotrophic PGPB on plant growth, few have looked at the molecular mechanisms involved. Hence, our mechanistic understanding of such interactions remains limited. Recently, Pankievicz and colleagues (2015) identified a few highly responsive genotypes of $S$. viridis when coinoculated with $A$. brasilense and $H$. seropedicae. One such genotype is A10.1, which sharply increased plant biomass upon inoculation and became a model plant for further nitrogen fixation studies. However, when Brachypodium distachyon genotypes were coinoculated with the same bacterial strains in a similar screening, the results were variable concerning the biomass response within genotypes (do Amaral et al. 2016). Unlike $S$. viridis, there was no $B$. distachyon genotype responsive to all of the growth parameters evaluated. Interestingly, $A$. brasilense and $H$. seropedicae established root association with all genotypes, even with those that showed no growth response. In our previous work, we demonstrated that $H$. seropedicae and $A$. brasilense transferred fixed nitrogen to the plant model $S$. viridis under laboratory conditions (Pankievicz et al. 2015). Although our study was limited to greenhouse-grown plants, recently, Pedrosa et al. (2019) demonstrated that the A. brasilense ammoniumexcreting HM053 strain also strongly promoted maize growth in the field, increasing production between 4.7 and $29 \%$, or 460.5 to $1,769.3 \mathrm{~kg} \mathrm{ha}^{-1}$. Earlier, Fox et al. (2016) showed that both wheat and maize plants obtained a substantial amount of fixed nitrogen from inoculation with an engineered ammoniumexcreting strain of Pseudomonas protegens Pf-5 X940. Taken together, many studies suggest that appropriately engineered PGPB diazotrophic inoculants can significantly reduce the need for nitrogen fertilizer in food and bioenergy crops. However, no major pathway or specific signal or regulation has been elucidated, which appears critical to establishing beneficial associations between diazotrophs and monocots.
Much remains to be discovered about the molecular and genetic determinants that drive the success of BNF in nonlegume plants. This includes the mechanisms that underlie recognition and establishment of efficient bacterial colonization, specific signal exchange, and observed genotype specificity between host and bacteria. Only a few studies have suggested particular genes and potential regulators as facilitating or impairing diazotrophic PGPB colonization (Bashan and de-Bashan 2010; Fukami et al. 2018; Giller and Merckx 2003; Monteiro et al. 2012; Reinhold-Hurek and Hurek 2011; Steenhoudt and Vanderleyden 2000).

Metabolic profiling of maize (Zea mays) roots in response to inoculation with $H$. seropedicae and $A$. brasilense demonstrated an increase in mannitol comparing fixing wild-type (fix+) and nonfixing (fix-) strains. The authors observed an increase in organic acids and carbohydrates in roots inoculated with a fix+ strain compared with those inoculated with a fixstrain or mock inoculated (Brusamarello-Santos et al. 2017). Moreover, a metabolomic comparison of $S$. viridis roots inoculated with either $H$. seropedicae fix + or fix-strains showed a high abundance of metabolites involved in nitrogen metabolism only with the fix+ strain (Agtuca et al. 2020). In another study, the authors investigated whether nitrogen metabolism affects the bacterial contribution to plant growth. S. viridis plants were challenged with $A$. brasilense FP2 and its $n t r C^{-}$ mutant (unable to metabolize nitrogen) (Kukolj et al. 2020) and $H$. seropedicae $\mathrm{SmR} 1$ and its nif $A^{-}$mutant (unable to fix nitrogen) (Agtuca et al. 2020). In both studies, the authors showed that wild-type and mutant strains could increase plant biomass upon inoculation, demonstrating that nitrogen fixation is not essential for plant growth promotion, at least under the laboratory conditions used in these studies.

The different ways that PGPB can affect plant growth have been exhaustively discussed (Backer et al. 2018; Compant et al. 2010; Vejan et al. 2016). Although BNF may contribute to PGPB-mediated plant growth promotion, it is not the sole determinant. Techniques using the stable ${ }^{15} \mathrm{~N}_{2}$ isotope should now be used to demonstrate the contribution of BNF to plant nutrition. Although not trivial, we encourage the research community to use these approaches as essential for documenting the contribution of BNF to cereals (Boddey et al. 2001; Pankievicz et al. 2019; Robinson 2001; Unkovich et al. 2008).

\section{Role of phytohormones.}

In addition to BNF, some bacterial strains can produce phytohormones such as gibberellic acid, auxin, cytokinin, and abscisic acid, all of which can dramatically impact plant growth. For instance, A. brasilense Ab-V5 has strong plantgrowth-promoting ability, previously documented to increase a variety of root traits (e.g., total root area and lateral root number), as well as nutrient uptake in 27 maize inbred lines growing under different nitrogen conditions and substrates (Zeffa et al. 2019). An increase of IAA concentration was observed that possibly favored plant biomass and root architecture modifications (Zeffa et al. 2019). Agtuca et al. (2020), investigating metabolomic changes in $S$. viridis upon inoculation with $H$. seropedicae fix+ or fix- strains, reported a significant enrichment of metabolites involved in the zeatin and riboflavin pathways in roots compared with control plants. That observation suggests that those compounds may modulate plant growth independently of nitrogen fixation. Considering the various effects of zeatin (cytokinin) on shaping root architecture in response to biotic and abiotic stimuli (Aloni et al. 2006; Silva-Navas et al. 2019), it is not surprising that this phytohormone could play a role in bacterial plant growth promotion. Interestingly, the enrichment of lumichrome, a photodegradation product of riboflavin, observed in roots inoculated with associative bacteria suggests a function 
similar to that previously shown in the legume-rhizobia (Dakora et al. 2015; Oldroyd et al. 2011; Stopka et al. 2017) and legume-mycorrhiza symbioses (Gouws et al. 2012) being involved in plant growth improvement. Given that hormonal levels can be affected by various environmental factors, including nitrogen limitation, one should be cautious in attributing cause and effect without further investigation. This issue points to the real difficulty in matching controls and experimental plants under nutrient limitation, especially in studies related to nitrogen.

Fukami et al. (2016) tested the effect of PGPB inoculant application using Azospirillum strains under field conditions. They observed an increase in maize root volume, plant height, and an increased number of tillers in wheat. They suggested that the effect on wheat was related to phytohormones produced by the bacteria (Fukami et al. 2016). Approximately $80 \%$ of the bacteria in the rhizosphere produce IAA, including those that interact with plants, which leads to the assumption that most plant growth effects are related to IAA (Patten and Glick 1996; Spaepen and Vanderleyden 2011; Vessey 2003).

Housh et al. (in press) demonstrated that BNF and auxin biosynthesis are not mutually exclusive microbial functions. They showed that the A. brasilense fix- strain (FP10) synthesizes auxin at a lower rate than the wild-type strain (FP2) and significantly less than the ammonium-excreting mutant HM053. These data reinforce that one must be cautious when assigning causes and effects of specific mutations because unknown or unmeasured pleiotropic effects may be significant contributors to the phenotypes observed (Housh et al. in press).

Although it is common to propose phytohormone production as a contributor to PGPB plant growth effects, to our knowledge, no study has appropriately compared the plant growth promotion effect of PGPB strains mutated in hormone production pathways to the corresponding wild-type strains. Without such experiments, it is impossible to attribute the observed effects solely to bacterial phytohormone production unequivocally. The reason for this may be genetic because genus Azospirillum, as an example, appears to have multiple pathways for IAA production (Cassán et al. 2020; Spaepen et al. 2007). Interestingly, Azoarcus olearius strains BH72 and DQS $-4^{\mathrm{T}}$ are efficient diazotrophic bacteria that strongly affect plant biomass while lacking genes to synthesize IAA. For instance, inoculation of rice and $S$. viridis with A. olearius DQS$4^{\mathrm{T}}$ led to a significant increase in root and shoot dry weight. In $S$. viridis, the plant-growth-promoting activity increased lateral root number and seed production (Faoro et al. 2017). These responses could be due to $\mathrm{BNF}$ or related to the differences between $\mathrm{C}_{3}$ and $\mathrm{C}_{4}$ plants and nitrogen use efficiency.

Quorum-sensing (QS) mechanisms play an essential role in regulating physiological processes in Gram-negative bacteria, including regulating bacteria-host interactions. For example, $\mathrm{N}$-acyl homoserine lactone (AHL) production can modulate plant growth and induce plant disease resistance (Schenk and Schikora 2015; Schikora et al. 2016). Auxin-related genes were upregulated in plants upon AHL application, while cytokinin genes were downregulated. Changes in the auxin and cytokinin balance are crucial to plant growth processes (Mathesius et al. 2003; Schikora et al. 2016; von Rad et al. 2008).

The study from Fukami et al. (2018) demonstrated that perception of AHL molecules via QS regulated biofilm, exopolysaccharide production, and motility of Azospirillum brasilense strain AbV5. These are critical bacterial features to ensure efficient plantmicrobe colonization. In contrast, strain Ab-V6 does not use the QS system but produces a lot of IAA, which can mimic a QS signal. More than that, they showed that plant growth promotion was negatively affected in Ab-V5 when the quorum-quenching strategy was applied but did not affect maize growth promotion by Ab-V6. Although the molecular crosstalk between diazotrophs and cereals has not been completely elucidated, the QS system appears to play a role in regulating the interaction and establishment of $A$. brasilense Ab-V5 with maize.

\section{Role of plant innate immunity.}

Plants are regularly challenged by a diverse community of microbes in their rhizosphere environment. The establishment of an association with diazotrophic bacteria can result in beneficial outcomes leading to BNF and growth promotion. An intriguing question is how plants can distinguish signals from beneficial bacteria from harmful pathogens to induce an appropriate response.

Investigations of genetic responses in different plant species identified a leucine-rich repeat-containing receptor-like-kinase (SHR5) whose expression was modulated upon diazotrophic association. In sugarcane, SHR5 expression was not affected by inoculation with nonpathogenic bacteria (Agrobacterium tumefaciens), pathogenic endophytic bacteria (Leifsonia xyli subsp. xyli), pathogenic fungus (Puccinia melanocephala), or a pathogenic virus; however, mRNA levels were significantly downregulated by inoculation with the endophytic bacteria Gluconacetobacter diazotrophicus, $H$. seropedicae, H. rubrisubalbicans, or Azospirillum brasilense (Vinagre et al. 2006). Similarly, in rice, a lectin-like receptor kinase 7 and an SHR5receptor-like kinase were repressed more than twofold in the presence of the endophyte $H$. seropedicae (BrusamarelloSantos et al. 2019). In addition to, Thomas and collaborators (2019) revealed that the receptor-like kinase SHR5 was differentially expressed during rice- $A$. brasilense interaction. In contrast, in rice, another homolog of SHR5 did not show differential expression upon endophytic colonization with Azoarcus olearius BH72 (Chen et al. 2015). Surface pattern recognition receptors such as receptor-like kinases are involved in plant immunity by sensing and responding to an external stimulus. The ability of PGPB to suppress the host immune response may be a critical component of their ability to both colonize and promote plant growth (Brusamarello-Santos et al. 2019; Chen et al. 2015; Turner et al. 2013).

The expression of a miRNA that regulates copper homeostasis and is involved in the defense response against pathogens increased in maize plants inoculated with $H$. seropedicae and Azospirillum brasilense, suggesting that the maize-diazotrophic colonization also modulates plant innate immunity-related functions (Thiebaut et al. 2014).

Apart from the few studies described above, to date, there is no specific signaling pathway describing nonlegume diazotrophic associative or endophytic bacteria interactions. Adopting a suitable model plant would accelerate efforts to define the molecular mechanisms involved in these associations. In this context, $S$. viridis has all of the attributes of a model system and has been successfully used for studying BNF-related effects in interaction with different beneficial bacterial strains.

\section{Adaptations in bacterial metabolism during host association.}

Bacteria can physiologically adapt to environmental conditions to engage in various competitions for host colonization and soil resources with other microorganisms. A dynamic metabolic adaption can confer a competitive advantage to beneficial bacteria before association. Alves et al. (2019), using $S$. viridis, demonstrated that plant growth promotion by $H$. seropedicae is dependent on polyhydroxybutyrate (PHB) production. Synthesis and subsequent depolymerization of PHB occur in the rhizosphere and the rhizoplane of $S$. viridis roots. PHB seems to be necessary for maintaining metabolic rates in the rhizosphere, a microaerobic environment optimal for BNF. The formation of PHB granules was also observed in the Burkholderia sp. Q208-sugarcane interaction (Paungfoo- 
Lonhienne et al. 2016). This was coupled with an upregulation expression of bd-type cytochromes, which suggests an increase in energy production to sustain conditions favorable to BNF. Outer membrane proteins, lipopolysaccharides, chemotaxis, and bacterial motility are essential for bacterial adhesion and internal colonization. For instance, $H$. seropedicae root colonization requires normal lipopolysaccharide production, because mutations of $r f b C$ and $r f b B$ led to an impaired bacterial attachment to maize roots (Balsanelli et al. 2010). A similar phenotype was observed in flagellum mutant $f l i C$, presumably affecting bacterial motility toward the host (Balsanelli et al. 2016). In rice, flagella of Azoarcus olearius act as a mediator of endophytic competence rather than acting as a microbeassociated molecular pattern inducing plant defense (Buschart et al. 2012). Similarly, $H$. seropedicae suppresses plant defense while activating iron uptake, expressing genes related to nitrogen fixation, cell motility, and cell wall synthesis (BrusamarelloSantos et al. 2019).

A comparative transposon mutagenesis sequencing approach in A. olearius DQS-4 ${ }^{\mathrm{T}}$ and $H$. seropedicae SmR1 associated with $S$. viridis identified over 100 genes for each bacterium that conveyed a competitive advantage during root colonization. Most of the genes identified specifically in A. olearius encoded metabolism functions, whereas genes identified in $H$. seropedicae were motility related, suggesting that each strain requires unique functions for competitive root colonization (do Amaral et al. 2020). The authors reported that mutations in an iron regulator gene enhanced the ability of A. olearius to associate with host roots in the early stages of colonization, either individually or in competition with the wild-type strain. Not surprisingly, PHB metabolism in $H$. seropedicae SmR1 appeared to play a role in root association (do Amaral et al. 2020), corroborating the previous studies mentioned above (Alves et al. 2019; Batista et al. 2018).

Dicarboxylates are essential components of the root exudate and play a crucial role in the chemotaxis of rhizospheric bacteria to plant roots (Reinhold et al. 1985). Chemotactic response and colonization efficiency of Azospirillum brasilense Sp7 toward finger millet, a C4 grass, was seriously affected by mutation of two specific dicarboxylate transporters (DctP and DctA). Moreover, plant growth promotion (root architecture) and in vitro nitrogen fixation of a $\operatorname{dctP} / \operatorname{dct} A$ double mutant of A. brasilense was severely compromised (Singh et al. 2019).

Bacterial secretion systems are protein complexes present in bacterial cell membranes for the secretion of substances. Nine different secretion systems have been described in bacteria (Chagnot et al. 2013). One primary function is to secrete virulence factors that enable pathogen infection. For many years, the secretion systems were thought to be involved in the interaction between beneficial diazotrophic bacteria and plants. Still, only recently, the type 6 secretion system (T6SS) was shown to be crucial for plant colonization by Azoarcus olearius BH72 under nitrogen fixation conditions (Jiang et al. 2019). This bacterium adapts its T6SS to the nitrogen-fixing lifestyle regulated by an as-yet-unknown posttranslational mechanism. The activation of T6SS was reported previously in proteomic analysis of rice roots colonized by $H$. rubrisubalbicans, a PGPB that can also act as a mild phytopathogen on some plant genotypes (Valdameri et al. 2017). During the interaction with rice, $H$. rubrisulbalbicans showed high Hcp protein expression levels (a secreted T6SS protein) and dinitrogenase reductase (NifH).

Given the diversity of PGPB strains, whose genomes suggest diverse metabolism, it seems likely that each PGPB will have its unique adaptation mechanisms to allow intimate plant association. Understanding the coevolution of plant-microbe interaction can explain some questions. Chaluvadi and Bennetzen
(2018), in a metagenomic study, demonstrated a host genetic contribution shaping the composition of $S$. viridis microbiota. The domestication of $S$. italica may have involved, in part, the selection of more beneficial bacteria-root associations. Gammaproteobacteria, Deltaproteobacteria, and Firmicutes, for example, were overrepresented in the wild species $S$. viridis rhizosphere, while Alphaproteobacteria were overrepresented in the domesticated S. italica rhizosphere. In the endophytic compartment, the Betaproteobacteria, including most of the nitrogen fixers, and Firmicutes were more abundant in the domesticated $S$. italica. In contrast, $S$. viridis was enriched for Gammaproteobacteria (Chaluvadi and Bennetzen 2018; Chen et al. 2003; Santi et al. 2013). This observation may reflect the broader adaptability of the wild-type $S$. viridis in contrast with the domesticated relative $S$. italica, which has selected specific associations in the root and rhizosphere. Previous studies postulate that ancient cultivars have more genomic plasticity to engage in diverse microbial associations (Bulgarelli et al. 2015; Wissuwa et al. 2009). Thus, identifying alleles of S. viridis related to promoting root and soil bacteria diversity and adaptability, together with those that respond to plant growth promotion, would help understand plant-bacteria interaction mechanisms. In some cases, the microbiome is considered the host's second genome that can be harnessed to improve plant traits for agricultural applications (Lakshmanan et al. 2014; Simon et al. 2019). Identifying suitable and functional microbiomes and their implications in improving sustainability are fundamental topics to be explored.

\section{S. viridis as a grass model plant for PGPB studies.}

Green foxtail millet (S. viridis) has been proposed as a model system for genetics and physiological studies of bioenergy feedstocks and panicoid crops such as switchgrass, sorghum, and maize (Brutnell et al. 2015; Doust et al. 2009; Li and Brutnell 2011; Muthamilarasan and Prasad 2015), and as a model for $\mathrm{C}_{4}$ photosynthesis (Brutnell et al. 2010, 2015; Huang et al. 2016). S. viridis has a short life cycle (approximately 6 to 8 weeks under greenhouse conditions), small plant stature (approximately $30 \mathrm{~cm}$ at maturity), no special requirements for growth, and a small, sequenced diploid genome (approximately $500 \mathrm{Mb}$ ); all essential features that make this plant an excellent model system. Methodologies for transformation by agrobacterium, floral dip, and CRISPR-Cas9 genome editing facilitates molecular and genomic studies utilizing $S$. viridis have been developed (Mamidi et al. 2020; Martins et al. 2015). As for PGPB studies, $S$. viridis is a robust model system for the dissection of complex traits and biotechnological improvement of plant-diazotrophic bacteria associations (Fig. 1) (Agtuca et al. 2020; Alves et al. 2019; Pankievicz et al. 2015).

\section{CONCLUDING REMARKS AND PERSPECTIVES}

Plant genetics and environment affect microorganism metabolism and, consequently, the plant-growth-promotion response. Genetic studies are critical to describe and reveal the steps and functionalities of diazotrophic bacteria and their effects on monocots. Since the 1970s, a voluminous literature has accumulated showing diazotrophs in soils and roots of nonleguminous plant species and their ability to promote plant growth. However, a somewhat confusing picture arises from these studies, which have yet to reveal any unique features that clearly define the power of PGPB to promote plant growth. Given the diversity of plant and bacterial genotypes involved, it would not be surprising to find that each association does have unique features. However, in all other plant-microbe associations, intense mechanistic studies have revealed common mechanisms that explain the interaction. In many cases, these 
studies have been aided by the scientific community's adoption of standard model systems. We strongly believe that similar intensive research on PGPB-monocot interactions will ultimately yield a clearer mechanistic understanding. Only through such knowledge will we see wider adoption of PGPB inoculants in agriculture, which requires greater field-to-field and crop-tocrop consistency and efficacy. The adoption of model systems for the study of PGPB-plant associations should be one aspect

\section{Setaria viridis as a model for diazotrophic PGPB interaction}

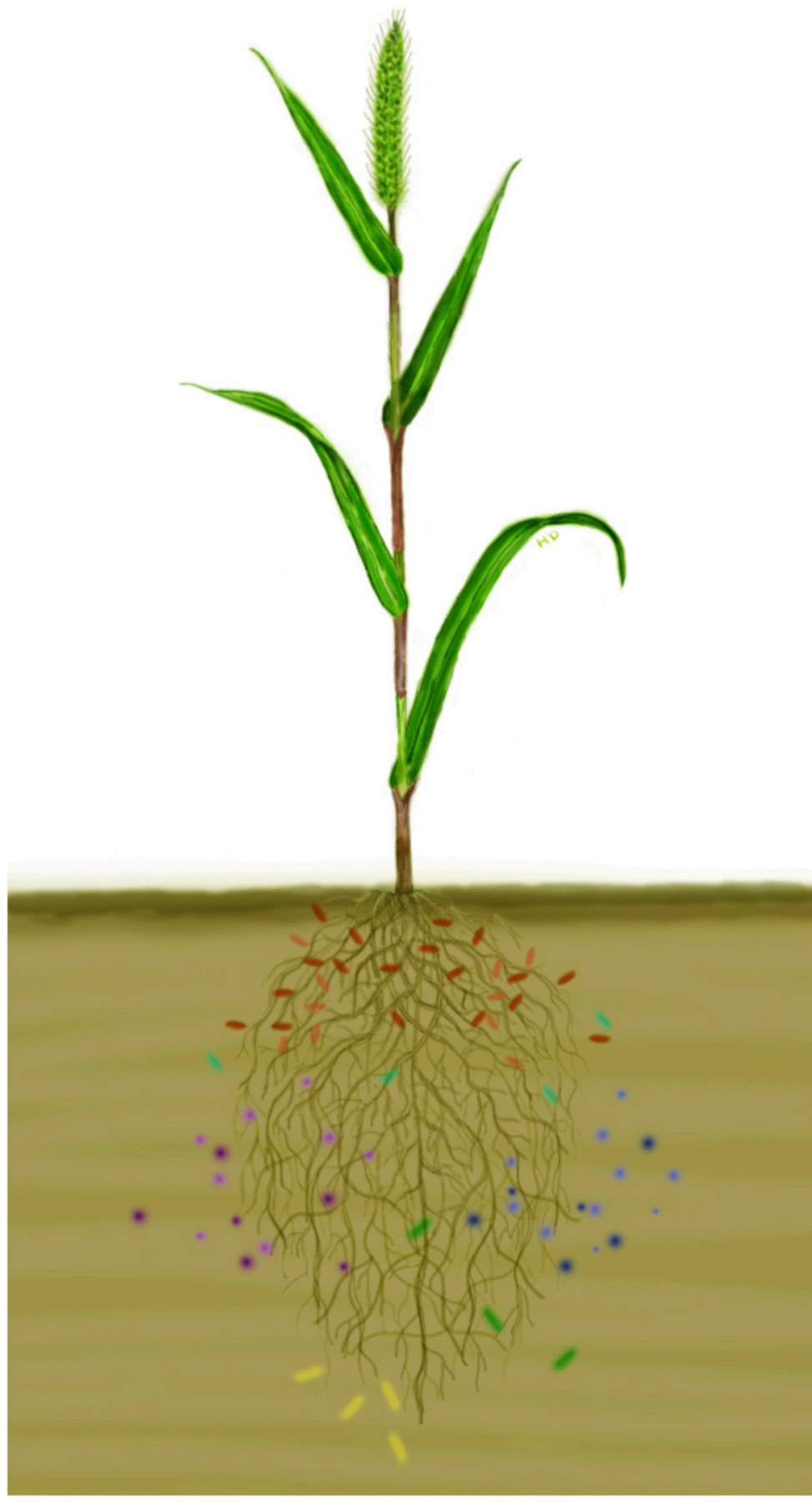

The benefits of plants hosting diazotrophic PGPB

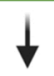

Acquisitions of nitrogen via $\mathrm{N}_{2}$ fixation (Pankievicz et al. 2015)

Enrichment of metabolites - cytokinin and riboflavin (Agtuca et al. 2020)

Auxin response to
nitrogen limitation
(Agtuca et al. 2020)

Above and below ground tissues biomass increase (Pankievicz et al. 2015, Faoro et al. 2017)

Fig. 1. Setaria viridis is an emerging model to study the plant molecular interactions with diazotrophic plant-growth-promoting bacteria (PGPB). S. viridis benefits from interaction with diazotrophic bacteria through the direct acquisition of fixed nitrogen, the enrichment of beneficial metabolites, an auxin response to nitrogen limitation, and an overall biomass increase. Specific molecular determinants confer an advantage to some bacteria to interact with $S$. viridis, such as the expression of nitrogen fixation genes, the secretion of ammonium, and polyhydroxybutyrate production. Characteristics such as auxin production and modifications in the nitrogen metabolism are relatively neutral to the success of these interactions. However, the expression of specific traits such as flagella can be disadvantageous to bacteria as symbionts. Boxes on the right represent the bacterial molecular strategies and mirror the bacteria's colors depicted on the root illustrations. 
of a greater focus on molecular mechanisms of these interactions. Integrative 'omics approaches from multiple research areas, including evolutionary studies, will help us to understand the action of PGPB on plants. Relative to other plant-microbe interactions, such studies are still underrepresented in the literature. A greater understanding of microbial community assembly and bacterial interaction affecting plant nutritional status is necessary to reveal the functional potential of plant microbiomes. The adoption of $S$. viridis as a grass model could answer essential questions. Here, we suggest that studies evaluating endophytic and rhizospheric bacteria using a more significant number of genotypes and mutant populations of $S$. viridis will explain the genotypic specificity seen with plant associations with better diazotrophic bacteria. Further investigations employing model bacterial strains with a model plant will be necessary to discover and determine the bacterial contribution to the host and the benefits for agricultural application.

\section{ACKNOWLEDGMENTS}

We thank H. N. Duong for conceiving and drawing the S. viridis plant illustration. The schematic boxes in Figure 1 were created with BioRender.

\section{LITERATURE CITED}

Agtuca, B. J., Stopka, S. A., Tuleski, T. R., do Amaral, F. P., Evans, S., Liu, Y., Xu, D., Monteiro, R. A., Koppenaal, D. W., Paša-Tolić, L., Anderton, C. R., Vertes, A., and Stacey, G. 2020. In-situ metabolomic analysis of Setaria viridis roots colonized by beneficial endophytic bacteria. Mol. Plant-Microbe Interact. 33:272-283.

Aloni, R., Aloni, E., Langhans, M., and Ullrich, C. I. 2006. Role of cytokinin and auxin in shaping root architecture: Regulating vascular differentiation, lateral root initiation, root apical dominance and root gravitropism. Ann. Bot. 97:883-893.

Alves, L. P. S., do Amaral, F. P., Kim, D., Bom, M. T., Gavídia, M. P., Teixeira, C. S., Holthman, F., Pedrosa, F. O., de Souza, E. M., Chubatsu, L. S., Müller-Santos, M., and Stacey, G. 2019. Importance of poly-3hydroxybutyrate metabolism to the ability of Herbaspirillum seropedicae to promote plant growth. Appl. Environ. Microbiol. 85:e02586-18.

Backer, R., Rokem, J. S., Ilangumaran, G., Lamont, J., Praslickova, D., Ricci, E., Subramanian, S., and Smith, D. L. 2018. Plant growthpromoting rhizobacteria: Context, mechanisms of action, and roadmap to commercialization of biostimulants for sustainable agriculture. Front. Plant Sci. 9:1473.

Baldani, J. I., and Baldani, V. L. D. 2005. History on the biological nitrogen fixation research in graminaceous plants: Special emphasis on the Brazilian experience. An. Acad. Bras. Cienc. 77:549-579.

Baldani, J. I., Caruso, L., Baldani, V. L. D., Goi, S. R., and Dobereiner, J. 1997. Recent advances in BNF with non-legume plants. Soil Biol. Biochem. 29:911-922.

Balsanelli, E., Serrato, R. V., de Baura, V. A., Sassaki, G., Yates, M. G., Rigo, L. U., Pedrosa, F. O., de Souza, E. M., and Monteiro, R. A. 2010. Herbaspirillum seropedicae $r f b B$ and $r f b C$ genes are required for maize colonization. Environ. Microbiol. 12:2233-2244.

Balsanelli, E., Tadra-Sfeir, M. Z., Faoro, H., Pankievicz, V. C. S., de Baura, V. A., Pedrosa, F. O., de Souza, E. M., Dixon, R., and Monteiro, R. A. 2016. Molecular adaptations of Herbaspirillum seropedicae during colonization of the maize rhizosphere. Environ. Microbiol. 18: 2343-2356.

Bashan, Y., and de-Bashan, L. E. 2010. How the plant growth-promoting bacterium Azospirillum promotes plant growth-A critical assessment. Pages 77-136 in: Advances in Agronomy, Vol. 108. D. L. Sparks, ed. Academic Press, San Diego, CA, U.S.A

Batista, M. B., Teixeira, C. S., Sfeir, M. Z. T., Alves, L. P. S., Valdameri, G., Pedrosa, F. O., Sassaki, G. L., Steffens, M. B. R., de Souza, E. M., Dixon, R., and Müller-Santos, M. 2018. PHB biosynthesis counteracts redox stress in Herbaspirillum seropedicae. Front. Microbiol. 9:472.

Boddey, R. M., Baldani, V. L. D., Baldani, J. I., and Döbereiner, J. 1986. Effect of inoculation of Azospirillum spp. on nitrogen accumulation by field-grown wheat. Plant Soil 95:109-121.

Boddey, R. M., Polidoro, J. C., Resende, A. S., Alves, B. J. R., and Urquiaga, S. 2001. Use of the ${ }^{15} \mathrm{~N}$ natural abundance technique for the quantification of the contribution of $\mathrm{N}_{2}$ fixation to sugar cane and other grasses. Aust. J. Plant Physiol. 28:889-895.
Boddey, R. M., Urquiaga, S., Alves, B. J. R., and Reis, V. 2003. Endophytic nitrogen fixation in sugarcane: Present knowledge and future applications. Plant Soil 252:139-149.

Brusamarello-Santos, L. C., Gilard, F., Brulé, L., Quilleré, I., Gourion, B., Ratet, P., de Souza, E. M., Lea, P. J., and Hirel, B. 2017. Metabolic profiling of two maize (Zea mays L.) inbred lines inoculated with the nitrogen fixing plant-interacting bacteria Herbaspirillum seropedicae and Azospirillum brasilense. PLoS One 12:e0174576.

Brusamarello-Santos, L. C. C., Alberton, D., Valdameri, G., Camilios-Neto, D., Covre, R., Lopes, K. de P., Tadra-Sfeir, M. Z., Faoro, H., Monteiro, R. A., Barbosa-Silva, A., Broughton, W. J., Pedrosa, F. O., Wassem, R., and de Souza, E. M. 2019. Modulation of defence and iron homeostasis genes in rice roots by the diazotrophic endophyte Herbaspirillum seropedicae. Sci. Rep. 9:10573.

Brutnell, T. P., Bennetzen, J. L., and Vogel, J. P. 2015. Brachypodium distachyon and Setaria viridis: Model genetic systems for the grasses. Annu. Rev. Plant Biol. 66:465-485.

Brutnell, T. P., Wang, L., Swartwood, K., Goldschmidt, A., Jackson, D., Zhu, X.-G., Kellogg, E., and Van Eck, J. 2010. Setaria viridis: A mode for C4 photosynthesis. Plant Cell 22:2537-2544.

Bulgarelli, D., Garrido-Oter, R., Münch, P. C., Weiman, A., Dröge, J., Pan, Y., McHardy, A. C., and Schulze-Lefert, P. 2015. Structure and function of the bacterial root microbiota in wild and domesticated barley. Cell Host Microbe 17:392-403.

Buschart, A., Sachs, S., Chen, X., Herglotz, J., Krause, A., and ReinholdHurek, B. 2012. Flagella mediate endophytic competence rather than act as MAMPS in rice-Azoarcus sp. strain BH72 interactions. Mol. PlantMicrobe Interact. 25:191-199.

Cassán, F., Coniglio, A., López, G., Molina, R., Nievas, S., de Carlan, C. L. N., Donadio, F., Torres, D., Rosas, S., Pedrosa, F. O., de Souza, E. Zorita, M. D., de-Bashan, L., and Mora, V. 2020. Everything you must know about Azospirillum and its impact on agriculture and beyond. Biol. Fertil. Soils 56:461-479.

Cavalcante, V. A., and Dobereiner, J. 1988. A new acid-tolerant nitrogenfixing bacterium associated with sugarcane. Plant Soil 108:23-31.

Chagnot, C., Zorgani, M. A., Astruc, T., and Desvaux, M. 2013. Proteinaceous determinants of surface colonization in bacteria: Bacterial adhesion and biofilm formation from a protein secretion perspective. Front. Microbiol. 4:303.

Chaluvadi, S., and Bennetzen, J. L. 2018. Species-associated differences in the below-ground microbiomes of wild and domesticated Setaria. Front. Plant Sci. 9:1183.

Chen, C., and Zhu, H. 2013. Are common symbiosis genes required for endophytic rice-rhizobial interactions? Plant Signal. Behav. 8: e25453.

Chen, W. M., Moulin, L., Bontemps, C., Vandamme, P., Béna, G., and Boivin-Masson, C. 2003. Legume symbiotic nitrogen fixation by $\beta$-proteobacteria is widespread in nature. J. Bacteriol. 185:7266-7272.

Chen, X., Miché, L., Sachs, S., Wang, Q., Buschart, A., Yang, H., Vera Cruz, C. M., Hurek, T., and Reinhold-Hurek, B. 2015. Rice responds to endophytic colonization which is independent of the common symbiotic signaling pathway. New Phytol. 208:531-543.

Compant, S., Clement, C., and Sessitsch, A. 2010. Plant growth-promoting bacteria in the rhizo- and endosphere of plants: Their role, colonization, mechanisms involved and prospects for utilization. Soil Biol. Biochem. 42:669-678.

Dakora, F. D., Matiru, V. N., and Kanu, A. S. 2015. Rhizosphere ecology of lumichrome and riboflavin, two bacterial signal molecules eliciting developmental changes in plants. Front. Plant Sci. 6:700.

do Amaral, F. P., Pankievicz, V. C., Arisi, A. C., de Souza, E. M., Pedrosa, F., and Stacey, G. 2016. Differential growth responses of Brachypodium distachyon genotypes to inoculation with plant growth promoting rhizobacteria. Plant Mol. Biol. 90:689-697.

do Amaral, F. P., Tuleski, T. R., Pankievicz, V. C. S., Melnyk, R. A., Arkin, A. P., Griffitts, J., Tadra-Sfeir, M. Z., de Souza, E. M., Deutschbauer, A., Monteiro, R. A., and Stacey, G. 2020. Diverse bacterial genes modulate plant root association by beneficial bacteria. MBio 11:e030378-20.

Dobereiner, J. 1961. Nitrogen-fixing bacteria of the genus Beijerinckia derx in the rhizosphere of sugar cane. Plant Soil 15:211-216.

Doust, A. N., Kellogg, E. A., Devos, K. M., and Bennetzen, J. L. 2009. Foxtail millet: A sequence-driven grass model system. Plant Physiol. 149:137-141

Eskin, N., Vessey, K., and Tian, L. 2014. Research progress and perspectives of nitrogen fixing bacterium, Gluconacetobacter diazotrophics, in monocot plants. Int. J. Agron. 2014:208383.

Faoro, H., Menegazzo, R. R., Battistoni, F., Gyaneshwar, P., do Amaral, F. P., Taulé, C., Rausch, S., Galvão, P. G., de los Santos, C., Mitra, S., Heijo, G., Sheu, S.-Y., Chen, W.-M., Mareque, C., Tadra-Sfeir, M. Z., 
Baldani, J. I., Maluk, M., Guimarães, A. P., Stacey, G., de Souza, E. M., Pedrosa, F. O., Cruz, L. M., and James, E. K. 2017. The oil-contaminated soil diazotroph Azoarcus olearius DQS- $4^{\mathrm{T}}$ is genetically and phenotypically similar to the model grass endophyte Azoarcus sp. BH72. Environ. Microbiol. Rep. 9:223-238.

Fox, A. R., Soto, G., Valverde, C., Russo, D., Lagares, A., Jr., Zorreguieta, Á., Alleva, K., Pascuan, C., Frare, R., Mercado-Blanco, J., Dixon, R., and Ayub, N. D. 2016. Major cereal crops benefit from biological nitrogen fixation when inoculated with the nitrogen-fixing bacterium Pseudomonas protegens Pf-5 X940. Environ. Microbiol. 18:3522-3534.

Fukami, J., Abrantes, J. L. F., Del Cerro, P., Nogueira, M. A., Ollero, F. J., Megías, M., and Hungria, M. 2018. Revealing strategies of quorum sensing in Azospirillum brasilense strains Ab-V5 and Ab-V6. Arch. Microbiol. 200:47-56.

Fukami, J., Nogueira, M. A., Araujo, R. S., and Hungria, M. 2016. Accessing inoculation methods of maize and wheat with Azospirillum brasilense. AMB Express 6:3.

Giller, K. E., and Merckx, R. 2003. Exploring the boundaries of N2-fixation in cereals and grasses: An hypothetical and experimental framework. Symbiosis 35:3-17.

Glick, B. R. 2012. Plant growth-promoting bacteria: Mechanisms and applications. Scientifica (Cairo) 2012:963401.

Gourion, B., Berrabah, F., Ratet, P., and Stacey, G. 2015. Rhizobiumlegume symbioses: The crucial role of plant immunity. Trends Plant Sci. 20:186-194.

Gouws, L. M., Botes, E., Wiese, A. J., Trenkamp, S., Torres-Jerez, I., Tang, Y., Hills, P. N., Usadel, B., Lloyd, J. R., Fernie, A. R., Kossmann, J., and van der Merwe, M. J. 2012. The plant growth promoting substance, lumichrome, mimics starch, and ethylene-associated symbiotic responses in lotus and tomato roots. Front. Plant Sci. 3:120.

Housh, A. B., Powell, G., Scott, S., Anstaett, A., Gerheart, A., Benoit, M., Waller, S., Powell, A., Guthrie, J. M., Higgins, B., Wilder, S. L., Schueller, M. J., and Ferrieri, R. A. Functional mutants of Azospirillum brasilense elicit beneficial physiological and metabolic responses in Zea mays contributing to increased host iron assimilation. ISME J. In press. doi.org/10.1038/s41396-020-00866-X

Huang, P., Shyu, C., Coelho, C. P., Cao, Y., and Brutnell, T. P. 2016. Setaria viridis as a model system to advance millet genetics and genomics. Front. Plant Sci. 7:1781.

Jiang, X., Beust, A., Sappa, P. K., Völker, U., Dinse, T., Herglotz, J., and Reinhold-Hurek, B. 2019. Two functionally deviating type 6 secretion systems occur in the nitrogen-fixing endophyte Azoarcus olearius $\mathrm{BH} 72$. Front. Microbiol. 10:459.

Kukolj, C., Pedrosa, F. O., de Souza, G. A., Sumner, L. W., Lei, Z., Sumner, B., do Amaral, F. P., Juexin, W., Trupti, J., Huergo, L. F., Monteiro, R. A., Valdameri, G., Stacey, G., and de Souza, E. M. 2020. Proteomic and metabolomic analysis of Azospirillum brasilensentr $C$ mutant under high and low nitrogen conditions. J. Proteome Res. 19:92-105.

Lakshmanan, V., Selvaraj, G., and Bais, H. P. 2014. Functional soil microbiome: Belowground solutions to an aboveground problem. Plant Physiol. 166:689-700.

Li, P., and Brutnell, T. P. 2011. Setaria viridis and Setaria italica, model genetic systems for the Panicoid grasses. J. Exp. Bot. 62:3031-3037.

Mamidi, S., Healey, A., Huang, P., Grimwood, J., Jenkins, J., Barry, K., Sreedasyam, A., Shu, S., Lovell, J. T., Feldman, M., Wu, J., Yu, Y., Chen, C., Johnson, J., Sakakibara, H., Kiba, T., Sakurai, T., Tavares, R., Nusinow, D. A., Baxter, I., Schmutz, J., Brutnell, T. P., and Kellogg, E. A. 2020. A genome resource for green millet Setaria viridis enables discovery of agronomically valuable loci. Nat. Biotechnol. 38: 1203-1210.

Martins, D. S., Reis, V. M., Schultz, N., Alves, B. J. R., Urquiaga, S., Pereira, W., Sousa, J. S., and Boddey, R. M. 2020. Both the contribution of soil nitrogen and of biological $\mathrm{N}_{2}$ fixation to sugarcane can increase with the inoculation of diazotrophic bacteria. Plant Soil 454:155-169.

Martins, P. K., Nakayama, T. J., Ribeiro, A. P., da Cunha, B. A. D. B., Nepomuceno, A. L., Harmon, F. G., Kobayashi, A. K., and Molinari, H. B. C. 2015. Setaria viridis floral-dip: A simple and rapid Agrobacterium-mediated transformation method. Biotechnol. Rep. 6:61-63.

Mathesius, U., Mulders, S., Gao, M., Teplitski, M., Caetano-Anolles, G., Rolfe, B. G., and Bauer, W. D. 2003. Extensive and specific responses of a eukaryote to bacterial quorum-sensing signals. Proc. Natl. Acad. Sci. U.S.A. 100:1444-1449.

Mendes, R., Garbeva, P., and Raaijmakers, J. M. 2013. The rhizosphere microbiome: Significance of plant beneficial, plant pathogenic, and human pathogenic microorganisms. FEMS Microbiol. Rev. 37:634-663.

Monteiro, R. A., Balsanelli, E., Wassem, R., Marin, A. M., BrusamarelloSantos, L. C. C., Schmidt, M. A., Tadra-Sfeir, M. Z., Pankievicz, V. C. S., Cruz, L. M., Chubatsu, L. S., Pedrosa, F. O., and Souza, E. M. 2012.
Herbaspirillum-plant interactions: Microscopical, histological and molecular aspects. Plant Soil 356:175-196. S/jrn>

Muthamilarasan, M., and Prasad, M. 2015. Advances in Setaria genomics for genetic improvement of cereals and bioenergy grasses. Theor. Appl. Genet. 128:1-14.

Oldroyd, G. E. D. 2013. Speak, friend, and enter: Signalling systems that promote beneficial symbiotic associations in plants. Nat. Rev. Microbiol. 11:252-263.

Oldroyd, G. E. D., Murray, J. D., Poole, P. S., and Downie, J. A. 2011. The rules of engagement in the legume-rhizobial symbiosis. Annu. Rev. Genet. 45:119-144.

Pankievicz, V. C. S., do Amaral, F. P., Santos, K. F., Agtuca, B., Xu, Y., Schueller, M. J., Arisi, A. C. M., Steffens, M. B. R., de Souza, E. M., Pedrosa, F. O., Stacey, G., and Ferrieri, R. A. 2015. Robust biological nitrogen fixation in a model grass-bacterial association. Plant J. 81: 907-919.

Pankievicz, V. C. S., Irving, T. B., Maia, L. G. S., and Ané, J. M. 2019. Are we there yet? The long walk towards the development of efficient symbiotic associations between nitrogen-fixing bacteria and nonleguminous crops. BMC Biol. 17:99.

Patten, C. L., and Glick, B. R. 1996. Bacterial biosynthesis of indole-3acetic acid. Can. J. Microbiol. 42:207-220.

Paungfoo-Lonhienne, C., Lonhienne, T. G. A., Yeoh, Y. K., Donose, B. C., Webb, R. I., Parsons, J., Liao, W., Sagulenko, E., Lakshmanan, P., Hugenholtz, P., Schmidt, S., and Ragan, M. A. 2016. Crosstalk between sugarcane and a plant-growth promoting Burkholderia species. Sci. Rep. 6:37389.

Pedrosa, F. O., Oliveira, A. L. M., Guimarães, V. F., Etto, R. M., Souza, E. M., Furmam, F. G., Gonçalves, D. R. P., Santos, O. J. A. P., Gonçalves, L. S. A., Battistus, A. G., and Galvão, C. W. 2019. The ammonium excreting Azospirillum brasilense strain HM053: A new alternative inoculant for maize. Plant Soil 451:45-56.

Peiffer, J. A., Spor, A., Koren, O., Jin, Z., Tringe, S. G., Dangl, J. L., Buckler, E. S., and Ley, R. E. 2013. Diversity and heritability of the maize rhizosphere microbiome under field conditions. Proc. Natl. Acad. Sci. U.S.A. 110:6548-6553.

Peoples, M. B., Herridge, D. F., and Ladha, J. K. 1995. Biological nitrogen fixation: An efficient source of nitrogen for sustainable agricultural production. Plant Soil 174:3-28.

Reinhold, B., Hurek, T., and Fendrik, I. 1985. Strain-specific chemotaxis of Azospirillum spp. J. Bacteriol. 162:190-195.

Reinhold-Hurek, B., and Hurek, T. 2011. Living inside plants: Bacterial endophytes. Curr. Opin. Plant Biol. 14:435-443.

Robinson, D. 2001. $\delta\left({ }^{5)} \mathrm{N}\right.$ as an integrator of the nitrogen cycle. Trends Ecol. Evol. 16:153-162.

Rosenblueth, M., Ormeño-Orrillo, E., López-López, A., Rogel, M. A., Reyes-Hernández, B. J., Martínez-Romero, J. C., Reddy, P. M., and Martínez-Romero, E. 2018. Nitrogen Fixation in Cereals. Front. Microbiol. 9:1794.

Roy, S., Liu, W., Nandety, R. S., Crook, A., Mysore, K. S., Pislariu, C. I., Frugoli, J., Dickstein, R., and Udvardi, M. K. 2020. Celebrating 20 years of genetic discoveries in legume nodulation and symbiotic nitrogen fixation. Plant Cell 32:15-41.

Santi, C., Bogusz, D., and Franche, C. 2013. Biological nitrogen fixation in non-legume plants. Ann. Bot. 111:743-767.

Schenk, S. T., and Schikora, A. 2015. AHL-priming functions via oxylipin and salicylic acid. Front. Plant Sci. 5:784.

Schikora, A., Schenk, S. T., and Hartmann, A. 2016. Beneficial effects of bacteria-plant communication based on quorum sensing molecules of the $\mathrm{N}$-acyl homoserine lactone group. Plant Mol. Biol. 90:605-612.

Silva-Navas, J., Conesa, C. M., Saez, A., Navarro-Neila, S., Garcia-Mina, J. M., Zamarreño, A. M., Baigorri, R., Swarup, R., and Del Pozo, J. C. 2019. Role of cis-zeatin in root responses to phosphate starvation. New Phytol. 224:242-257.

Simon, J. C., Marchesi, J. R., Mougel, C., and Selosse, M. A. 2019. Hostmicrobiota interactions: From holobiont theory to analysis. Microbiome 7:5.

Singh, V. S., Tripathi, P., Pandey, P., Singh, D. N., Dubey, B. K., Singh, C., Singh, S. P., Pandey, R., and Tripathi, A. K. 2019. Dicarboxylate transporters of Azospirillum brasilense Sp7 play an important role in the colonization of finger millet (Eleusine coracana) roots. Mol. PlantMicrobe Interact. 32:828-840.

Spaepen, S., and Vanderleyden, J. 2011. Auxin and plant-microbe interactions. Cold Spring Harb. Perspect. Biol. 3:a001438.

Spaepen, S., Vanderleyden, J., and Remans, R. 2007. Indole-3-acetic acid in microbial and microorganism-plant signaling. FEMS Microbiol. Rev. 31:425-448.

Steenhoudt, O., and Vanderleyden, J. 2000. Azospirillum, a free-living nitrogen-fixing bacterium closely associated with grasses: Genetic, biochemical and ecological aspects. FEMS Microbiol. Rev. 24:487-506. 
Stopka, S. A., Agtuca, B. J., Koppenaal, D. W., Paša-Tolić, L., Stacey, G., Vertes, A., and Anderton, C. R. 2017. Laser-ablation electrospray ionization mass spectrometry with ion mobility separation reveals metabolites in the symbiotic interactions of soybean roots and rhizobia. Plant J. 91:340-354.

Thiebaut, F., Rojas, C. A., Grativol, C., Motta, M. R., Vieira, T., Regulski, M., Martienssen, R. A., Farinelli, L., Hemerly, A. S., and Ferreira, P. C. G. 2014. Genome-wide identification of microRNA and siRNA responsive to endophytic beneficial diazotrophic bacteria in maize. BMC Genomics 15:766.

Thomas, J., Kim, H. R., Rahmatallah, Y., Wiggins, G., Yang, Q., Singh, R., Glazko, G., and Mukherjee, A. 2019. RNA-seq reveals differentially expressed genes in rice (Oryza sativa) roots during interactions with plantgrowth promoting bacteria, Azospirillum brasilense. PLoS One 14:e217309.

Trivedi, P., Leach, J. E., Tringe, S. G., Sa, T., and Singh, B. K. 2020. Plantmicrobiome interactions: From community assembly to plant health. Nat. Rev. Microbiol. 8:607-621.

Turner, T. R., James, E. K., and Poole, P. S. 2013. The plant microbiome. Genome Biol. 14:209.

Unkovich, M., Herridge, D., Peoples, M., Cadisch, G., Boddey, R., Giller, K., Alves, B., and Chalk, P. 2008. Measuring plant-associated nitrogen fixation in agricultural systems. Australian Centre for International Agricultural Research Publ. MN136.

Valdameri, G., Alberton, D., Moure, V. R., Kokot, T. B., Kukolj, C., Brusamarello-Santos, L. C. C., Monteiro, R. A., Pedrosa, F. O., and de
Souza, E. M. 2017. Herbaspirillum rubrisubalbicans, a mild pathogen impairs growth of rice by augmenting ethylene levels. Plant Mol. Biol. 94:625-640.

Vejan, P., Abdullah, R., Khadiran, T., Ismail, S., and Boyce, A. N. 2016. Role of plant growth promoting rhizobacteria in agricultural sustainability-A review. Molecules 21:573.

Vessey, J. K. 2003. Plant growth promoting rhizobacteria as biofertilizers. Plant Soil 255:571-586.

Vinagre, F., Vargas, C., Schwarcz, K., Cavalcante, J., Nogueira, E. M., Baldani, J. I., Ferreira, P. C. G., and Hemerly, A. S. 2006. SHR5: A novel plant receptor kinase involved in plant- $\mathrm{N}_{2}$-fixing endophytic bacteria association. J. Exp. Bot. 57:559-569.

Von Bülow, J. F., and Döbereiner, J. 1975. Potential for nitrogen fixation in maize genotypes in Brazil. Proc. Natl. Acad. Sci. U.S.A. 72: 2389-2393.

von Rad, U., Klein, I., Dobrev, P. I., Kottova, J., Zazimalova, E., Fekete, A., Hartmann, A., Schmitt-Kopplin, P., and Durner, J. 2008. Response of Arabidopsis thaliana to N-hexanoyl-DL-homoserine-lactone, a bacterial quorum sensing molecule produced in the rhizosphere. Planta 229:73-85.

Wissuwa, M., Mazzola, M., and Picard, C. 2009. Novel approaches in plant breeding for rhizosphere-related traits. Plant Soil 321:409.

Zeffa, D. M., Perini, L. J., Silva, M. B., de Sousa, N. V., Scapim, C. A., de Oliveira, A. L. M., do Amaral Júnior, A. T., and Gonçalves, L. S. A. 2019. Azospirillum brasilense promotes increases in growth and nitrogen use efficiency of maize genotypes. PLoS One 14:e0215332. 